\title{
Employee Responses to Empowering Leadership: A Meta-Analysis
}

\author{
Minseo Kim, Terry A. Beehr, and Matthew S. Prewett \\ Department of Psychology \\ 233 Sloan Hall \\ Central Michigan University \\ Mount Pleasant, Michigan 48859, U.S.A.
}

Some of these data were presented at the $32^{\text {nd }}$ Annual Conference of the Society for Industrial and Organizational Psychology in Orlando FL.

\section{Author biographies}

Minseo Kim is an I/O Psychology PhD student at Central Michigan University. Her research interests include occupational stress, leadership, motivation, careers, job crafting, and employee well-being.

Terry A. Beehr is a Professor of Psychology and member of the I/O Psychology faculty at Central Michigan University. His research interests include occupational stress, retirement, leadership, motivation, and careers.

Matthew S. Prewett is an Associate Professor of Psychology and member of the I/O Psychology faculty at Central Michigan University. His research interests include team performance, team personality composition, leadership, training, and virtual communications.

\section{Corresponding Author:}

Minseo Kim, Department of Psychology, Central Michigan University, 233 Sloan Hall, Mount Pleasant, MI 48859, USA. Email: minseokim0331@gmail.com 


\begin{abstract}
A recent and growing number of studies examined how empowering leadership influences employee outcomes. At the individual level, we meta-analyzed 55 independent samples to determine the association between empowering leader behaviors and subordinates' responses. Results confirmed the positive links of empowering leadership with evaluations of the leader as well as with employee motivation and resources, attitudes, and performance; the strongest correlation was between empowering leadership and attitudes towards the leader $(\rho=.59)$, whereas the weakest correlation was for empowering leadership with behavioral and performance outcomes $(\rho=.31)$. However, the relationship of empowering leadership with subordinates' emotions was not significant. Examination of potential moderators, including rating sources, nationality of sample, gender, and industry, did not explain much of the heterogeneity in the results. In sum, findings highlight the potential benefit of empowering leadership for individual and organizational outcomes. Thus, more knowledge about what causes empowering leadership could be useful.
\end{abstract}

Keywords: empowering leadership, outcomes, meta-analysis 


\section{Employee Responses to Empowering Leadership: A Meta-Analysis}

In dynamic working environments, employee empowerment could give organizations advantages in acquiring and sustaining competitive positions in their markets, if it results in favorable employee attitudes, motivation, and behaviors. Because empowered employees believe in their ability to perform meaningful work and to influence their environments, they tend to work independently and exhibit adaptive behaviors beyond their formal work roles (Amundsen \& Martinsen, 2014a; Griffin, Neal, \& Parker, 2007; Martin, Liao, \& Campbell, 2013; Spreitzer, 1995; Thomas \& Velthouse, 1990). Indeed, some studies have shown positive effects of empowerment on some subordinates' work outcomes (Maynard, Gilson, \& Mathieu, 2012; Maynard, Luciano, D’Innocenzo, Mathieu, \& Dean, 2014; Seibert, Silver, \& Randolph, 2004; Seibert, Wang, \& Courtright, 2011).

Early work on the construct of empowerment was related to motivational theories, especially to the (1) job characteristics model (Hackman \& Oldham, 1980) and (2) Bandura's work on perceived self-efficacy $(1982,1997)$. According to the former theory, particular job characteristics, including autonomy and feedback, cause positive psychological states including felt responsibility, which is conceptually related to empowerment. Autonomy, feedback, and responsibility constitute elements of intrinsic motivation in job design and thus indirectly predict favorable outcomes. In addition to the potential for job redesign to provide employees with greater autonomy and control resulting in empowerment, the individual difference of selfefficacy may also have an effect. Self-efficacy is individual's belief or confidence that he or she can perform tasks successfully (Bandura, 1997). Self-efficacy is a foundation of motivation and performance achievement, making employees believe that their performance depends on their efforts and actions, and thus intrinsically motivating them to work hard to produce desired results 
(Bandura, 1997). Thomas and Velthouse (1990) argued that empowerment, as a broader motivational state than just self-efficacy, is an active orientation toward work, motivating employees by making them feel responsible for their own work effectiveness. Empowering leadership is related to the job design perspective because leaders have the potential to influence their own subordinates' job design by for example, allowing them more discretion or varied assignments. Empowering leaders can be seen as using high involvement management approaches by giving authority and responsibility to subordinates (Leach, Wall, \& Jackson, 2003).

Empowering leadership bears some similarities to other prominent theories of leadership. The most similar of these is probably participative leadership or participative management, but this is a narrower construct than empowering leadership. Participative leadership has been recognized and advocated by writers for almost a century. Its meaning has varied, sometimes widely, but its main focus has always been on the individual subordinate's or group's participation in decision making that would normally be done by the leader in a classically structured, hierarchical organization. Follett (1926) argued for a participative management style in which expertise, often found in subordinates, would determine who made important decisions for a business unit, often resulting in decisions determined by a combination of influence from supervisors and subordinates. Likert (1961) advocated participative group decision-making as the most effective style, which he labeled System 4, although most of his writing and examples seemed to apply to management groups. Vroom and Yetton's (1973) approach also tended to focus on management, proposing a normative leadership decision-making model in which a range of styles from autocratic to group participative decision making was advocated, depending on the nature of several situational characteristics. Finally, Koopma and Wierdsma (1998) 
defined participative leadership primarily by its democratic decision-making process. Overall, descriptions of participative leadership have a long history; they have not always been consistent, but the most key feature is participation specifically in decision making. In addition, we observe somewhat strong but secondary emphases on participative leadership at management levels and on participation as a group more than delegation to individuals.

Empowering leadership is a conceptually broader construct, because it includes more than participation in decision making, instead allowing subordinates to take charge of any part of their work; empowering leadership also does not focus on specific levels or types of jobs and does not specify participation by groups versus individuals. In addition to differences in the constructs, empowering leadership measures often include participative decision-making behaviors in the form of subscales, another indication that participative leadership is meant to be a narrower construct included within a broader empowering leadership construct (e.g., Arnold, Arad, Rhoades, \& Drasgow, 2000). Empirically, empowering leadership and consultation (a term including participative leadership; Leana, 1987) were shown to have distinct antecedents and consequences (Leana, 1987; Yukl \& Fu, 1999). Moreover, although empowering leadership includes participation or delegation, by definition, empowering leadership also consists of giving subordinates a strong feeling of self-determination, trust, goal focus, self-confidence, and development support (Ahearne, Mathieu, \& Rapp, 2005; Amundsen \& Martinsen, 2014b; Konczak, Stelly, \& Trusty, 2000; Manz \& Sims, 1987).

Secondarily, empowering leadership shares some similarities with Leader-Member Exchange (LMX) and transformational leadership. LMX means that managers develop a unique quality of relationship with each of their subordinates, rather than having the same relationship across all subordinates. LMX and empowering leadership have in common that both can refer to 
the dyadic relationship between leader and subordinate. However, these two leadership styles are different, because some subordinates, especially new employees, may perceive a high quality of the exchange relationship when leaders exhibit directive behaviors and assign goals or work without power sharing (Sharma \& Kirkman, 2015). That is, LMX does not necessarily imply delegation of power. Thus, empowering leadership may lead to favorable LMX with some employees more than others. Leaders may differentiate among subordinates according to their competence, performance, and other factors such as leaders' expectations or mutual liking in deciding how to treat each one (Sparrowe \& Liden, 1997).

Transformational leaders encourage subordinate self-development, provide a vision for the future, and pay attention to the subordinate's needs by exhibiting four kinds of behaviors: idealized influence, intellectual stimulation, inspirational motivation, and individualized consideration (Bass \& Riggio, 2006). However, unlike empowering leaders, transformational leaders may display these four behaviors without transferring power to subordinates, and subordinates are not normally allowed participation in making the vision itself (Amundsen \& Martinsen, 2014b; Sharma \& Kirkman, 2015). Importantly, factor analyses have shown that empowering leadership is empirically distinct from transformational, transactional, and directive leadership (Pearce, Sims, Cox, Ball, Schnell, Smith, \& Trevino, 2003). Taken together, empowering leadership can be a distinct type of leadership, conceptually and empirically, through emphases on different aspects of the leadership process, such as encouraging subordinates to take initiative, emphasizing subordinates' focus on goals, showing confidence in subordinates in order to increase their sense of self-efficacy and motivation, and providing developmental support in order to enhance subordinates' skills (Ahearne et al., 2005; Amundsen \& Martinsen, 2014b; Arnold et al., 2000; Zhang \& Bartol, 2010). 
Theoretically, empowering leadership can be an effective leadership style for both employees and organizations because its behaviors generate intrinsic motivation of employees, thereby linking to favorable outcomes including job satisfaction, engagement, creativity, and work performance and extra-role behaviors (Amundsen \& Martinson, 2015; Humborstad, Nerstad, \& Dysvik, 2014; Raub \& Robert, 2010; Vecchio, Justin, \& Pearce, 2010; Tuckey, Bakker, \& Dollard, 2012; Zhang \& Zhou, 2014). However, not all studies find these favorable results for empowering leadership. Some studies proposed empowering leadership might have detrimental consequences, perhaps because empowering leader behaviors focusing on high autonomy in decision-making and on task delegation might increase task uncertainty, thereby resulting in reduced performance (Cordery, Morrison, Wright, \& Wall, 2010; Martin et al., 2013). Similarly, empowering leadership has decreased work performance through increasing employees' job-induced tension (Cheong, Spain, Yammarino, \& Yun, 2016). Potential costs due to initial performance delay were also found, probably because empowering leader behaviors focused on modeling and idea exchanges instead of job performance (Lorinkova, Pearsall, \& Sims, 2013). Moreover, inverted U-shaped relationships between empowering leadership and employee job performance were suggested (Lee, Cheong, Kim, \& Yun, 2016). Other studies found no direct effects of empowering leadership on performance (Srivastava, Bartol, \& Locke, 2006). Further, some employees benefited from empowering leaders' behaviors, but not others (Ahearne et al., 2005). Overall, the effect of empowering leadership looks quite complex and uncertain. Therefore, a meta-analytic approach will help clarify the situation and determine the extent to which the display of empowering leadership is beneficial for work outcomes and to derive a more accurate estimate of its magnitude of influence on the variety of outcomes that have been examined in the empirical literature. 
Sharma and Kirkman (2015) reviewed and summarized the empowering leadership literature, but a quantitative review of the consequences of empowering leadership has not yet been provided. We fill this gap in the leadership literature with a systematic meta-analysis on how empowering leadership relates to individual and organizational outcomes. This study helps integrate research findings to better understand the correlates of empowering leadership. Because research on empowering leadership is in a relatively early stage, this review also allows us to uncover gaps in the literature to guide future empirical and theoretical developments. Further, we examine potential moderators of empowering leadership-outcomes relationships, which may provide understanding of any inconsistent effects of empowering leadership on its criterion domain.

\section{Outcomes of Empowering Leadership}

We first reviewed empowering leadership studies that have been conducted so far and classified outcomes of empowering leadership into five categories: evaluations of leaders, motivation and resources, emotions, attitudes, and performance (Figure 1). Table 1 contains all categories of outcomes used and gives examples of the concepts under each category. The metaanalysis thus examined the relationship between empowering leadership and those five subordinate outcomes. Multiple measures were considered in each of these outcome categories.

Some studies examined attitudes or assessments that employees hold about leaders' empowering behaviors. These studies argued that leader's empowering behaviors are positively related to subordinates' trust in the leader (e.g., Bobbio, Bellan, \& Manganelli, 2012) and perceived leader effectiveness (e.g., Tekleab, Sims Jr, Yun, Tesluk, \& Cox, 2008). Empowering leader behaviors may help to create trusting and supportive environments in which leaders show respect for the subordinate. Because of this, subordinates often evaluate their leaders' 
effectiveness favorably due to developing trust in their leader based on both affective and cognitive states.

Hypothesis 1. Empowering leadership will be related to positive evaluations of leaders.

There is broad agreement that empowering leadership contributes to generating intrinsic motivation and resources in some form, such as psychological empowerment, self-efficacy, role clarity, and goal orientation. Employee motivation and psychological resources are important components influencing work outcomes (Bakker \& Demerouti, 2007; Spreitzer, 1995). Some forms of psychological resources, such as self-efficacy and optimism, are linked to positive outcomes because they make employees feel capable of controlling their work environment as well as feel more resilient, which can result in positive appraisals of demanding or otherwise adverse situations (Xanthopoulou, Bakker, Demerouti, \& Schaufeli, 2007). In other words, employees working in a resourceful environment (e.g., one with autonomy, opportunities to learn, and high-quality coaching) feel more confident about their capabilities and create favorable working environments that facilitate their goal achievement, which consequently leads to other positive individual and organizational outcomes.

Employees' psychological empowerment may be one of the profitable personal resources in the workplace; 23 studies included in our meta-analysis found that empowering leadership is an influential leadership style for promoting employees' perceptions of psychological empowerment consisting of meaning, competence, self-determination, and impact. Self-efficacy, an individual's belief in the ability to achieve desired outcomes across a variety of tasks and situations (Bandura, 1997), is also enhanced through empowering leaders' guidance, coaching, and modeling. In a similar vein, organization-based self-esteem (i.e., employees' beliefs about their own value and competence as organizational members within the context of the workplace; 
Pierce, Gardner, Cummings, \& Dunham, 1989) is promoted by empowering leadership. Increased job autonomy may convey to employees that they are trusted and worthy organization members (influencing their efficacy and esteem). Empowering leader behaviors such as offering personal and professional challenges with high standards also allow employees to experience self-value and competence at work. Additionally, Martínez-Córcoles, Gracia, Tomás, and Peiró (2014) suggested that empowering leader behaviors such as sharing information on the organization's mission as well as encouraging participative goal-setting and decision making increase employees' a sense of control and understanding their roles and expectations. Finally, employee goal orientation was also found to be positively related to empowering leadership; when individuals high in goal orientation work with empowering leaders, they are more likely to be motivated in their work and make more effort, thereby increasing their level of performance. Hypothesis 2. Empowering leadership will be positively related to the development of employee motivation and resources.

Employees' positive attitudes including job satisfaction, commitment, work engagement, and favorability toward knowledge sharing were predicted by empowering leaders' behaviors in some studies. Subordinates who experienced empowering leadership reported higher levels of job satisfaction, probably because empowering leaders emphasize their discretion in setting goals and determining work procedures, which helps employees to understand and perform whole pieces of work and eventually makes it possible for subordinates to derive meaning from the job (e.g., Amundsen \& Martinsen, 2014b). Employees also reciprocated beneficial empowering leader behaviors by demonstrating higher commitment when they perceived that leaders gave them individualized support and sufficient opportunity to voice opinions in their work (e.g., Den Hartog \& De Hoogh, 2009). Autonomy, one of the core factors of empowering leadership, has 
been identified as a predictor of work engagement (Albrecht \& Andreetta, 2011); empowering leaders can promote autonomy-related states such as self-leadership, challenging work, and opportunity thinking, by encouraging subordinates to view unsuccessful performance as a chance to learn, providing employees with opportunities to satisfy their higher order needs and triggering positive attitudes towards the job. Additionally, some studies found that employees feel more positive about sharing their ideas and knowledge when they receive recognition about their contribution from their empowering leaders (Eze, Goh, Goh, \& Tan, 2013). Thus, empowering leader behaviors also facilitate positive attitudes about communication among employees, thereby promoting opportunities to share their knowledge (Xue, Bradley, \& Liang, 2011).

Hypothesis 3. Empowering leadership will be positively related to employee attitudes. In addition to employee attitudes, which are both evaluative and affective responses toward specific work-related objects, empowering leadership has also been studied in relation to emotions, which are stronger affective states that may or may not have a specific object or referent. Only a few studies examined employee emotions relevant to empowering leadership, and most of them examined (reduced) negative emotions (e.g., Cheong et al., 2016), contrary to the studies of employee attitudes, which were mostly about (increased) positive attitudes. Employees working with empowering leaders are more likely to have autonomy and positive work experiences, and thereby they may feel less burnout and tension from their job as well as possess less cynical attitudes. Prior studies suggested that experiences of negative emotions (e.g., emotional exhaustion and cynicism) may result from too many demands with few resources (Schaufeli \& Bakker, 2004). From the perspective of COR theory (Conservation of Resources; Hobfoll, 2011), positive work experiences resulting from empowering leadership may help 
employee obtain, retain, and foster enduring personal resources or the necessary energy. That is, empowering leadership as a resource is likely to help employee better deal with work-related issues, thereby counteracting the effect of negative emotions.

Hypothesis 4. Empowering leadership will be negatively related to employee negative emotions.

Finally, consequences of empowering leadership on performance include creativity and innovative behaviors, in-role performance, contextual performance, and withdrawal behaviors. Results for the effects of empowering leadership on creativity and innovative behaviors seem to support the argument that empowering leadership has positive relationships with these outcomes (Gkorezis, 2016; Zhang \& Zhou, 2010; 2014). Additionally, empowering leadership may have negative effects on employee withdrawal behaviors such as absenteeism and turnover intentions (Dewettinck \& van Ameijde, 2011; Kim \& Beehr, 2016b); that is, an employee's intent to stay with or quit the organization depends on the work experiences and interactions with the leader. This would happen if the leader creates positive and trusting working relationships or working situations that are generally satisfying.

However, findings regarding job and contextual performance, which are the most examined performance outcomes of empowering leadership, are inconsistent. There are also arguments that the relationship of empowering leadership with in-role and extra-role performance (which are similar to contextual performance) is not linear (e.g., Humborstad et al., 2013). Furthermore, there can be a cost of autonomy (e.g., Langred \& Moye, 2004) if it requires cognitive effort and distraction, and based on role theory, autonomy might entail some role ambiguity and conflict (Kahn, Wolfe, Quinn, Snoek, \& Rosenthal, 1964). Therefore, 
empowerment constitutes control and freedom, but that can either increase and/or diminish employees’ work performance (e.g., Jeong, Gong, \& Ju, 2016).

Nevertheless, the majority of thinking and research seems to indicate that empowering leadership has mostly favorable effects on performance variables. That is, empowering leadership should facilitate employee performance (e.g., Raub \& Robert, 2010), because empowering leaders stimulate employees' autonomous motivation; based on self-determination theory, this motivation leads employees who are given greater independence from higher authority to show higher levels of job and contextual performance. Furthermore, empowering leaders' modeling, coaching, and informing behaviors provide employees with task-relevant knowledge and information so that they can perform their tasks correctly. Theoretically, there are multiple reasons to assume that empowering leadership will likely have effects on overall performance.

Hypothesis 5. Empowering leadership will be positively related to employee performance.

\section{Moderators of Empowering Leadership}

We also planned to examine two potential moderators of the relationship between empowering leadership and outcomes: the source of the criterion measure and the nation in which the study was conducted (as a surrogate for culture). Regarding whether source of the criterion measure (self-report vs. other ratings) moderated the relationship between empowering leadership and performance, measurement source may have influence effect size due to common method variance possibly enhancing the effect size. Empowering leadership was typically measured from the subordinates' point of view, but some criteria were measured from the subordinates' and some from the leaders' points of view. 
Relationships between leadership styles and employee reactions also may be contingent on cultural values, including power distance, individualism-collectivism, and/or uncertainty avoidance (Kirkman, Chen, Farh, Chen, \& Lowe, 2009; Lian, Ferris, \& Brown, 2012). For example, power distance is defined as "the extent to which the less powerful members of institutions and organizations within a country expect and accept that power is distributed unequally" (Hofstede, 2001, p. 98). Power distance plays an important role in how employees react to supervisors who hold higher positions in the organization (Kirkman et al., 2009). Some Asian countries such as China and South Korea are typically known as high power distance societies, whereas North American countries such as Canada and the United States can be considered relatively low power distance cultures (Javidan, Dorfman, De Luque, \& House, 2006). Empowering leadership may have a weaker effect on employee outcomes when employees were in high power distance societies, because they tend to rely on superiors and thus may expect and accept charismatic and/or autocratic leadership better than consultative and participative leadership. Likewise, Asian countries tend to differ from North American countries on the cultural domain of uncertainty avoidance, in which Asians express a weaker preference for uncertain or ambiguous situations than their North American counterparts (Hofstede, 2001). As a result, another reason empowering leadership may be less effective in Asian countries is that such empowerment behaviors induce role ambiguity or uncertainty over the responsibilities of the subordinate as compared to the responsibilities of the leader. Examination of specific cultural dimensions was not feasible due to the lack of studies measuring them. However, indirect evidence of their cumulative effect might be observed from cross-national comparisons, given the correlation between cultural values and nationality. 


\section{Method}

Literature search and inclusion criteria

A literature search was conducted using the PsycINFO, ProQuest, and Google Scholar databases for all articles using the search terms empowering leadership, empowering behavior, empowering management, and empowerment climate/practices. To minimize publication bias or the "file drawer problem," the search included unpublished studies such as dissertations and papers presented at relevant conference proceedings for the Academy of Management and the Society for Industrial Organizational Psychology from 2011 to 2017. From the initial search, 65 articles contained relevant data. Among them, we eliminated 10 articles for the following reasons: (1) There was no apparent use of an empowering leadership measure as it is conceptualized in the empowering leadership literature; (2) there were no usable effect sizes in the study; (3) there were no quantitative empirical data collected; (4) and/or there were only team-level outcomes. Studies on team-level effects of empowering leadership could not be satisfactorily examined due to the small number of available studies and the inconsistencies in the outcomes measured. This is unfortunate, as leadership is intimately connected with teamlevel activities, and empowering leadership behaviors can facilitate team performance and functioning. Indeed, the limited research has found that empowering leadership was positively related to team efficacy, empowerment, knowledge sharing, and team performance (Chen, Kirkman, Kanfer, Allen, \& Rosen, 2007; Magni \& Maruping, 2013; Srivastava et al., 2006; Tung \& Chang, 2011). .

Depending on the theoretical arguments made in hypotheses, some studies used only some of empowering leadership subscales, such as participative decision-making, informing, or showing concern. In such cases, the correlations for the separate measures were averaged to 
create a single sample correlation for empowering leadership. We did not include any studies in which only one dimension of empowering leadership behaviors was used. For example, studies on participative leadership often used one of subscales, adopted from the Empowering Leadership Questionnaire (Arnold et al., 2000) to measure participative leadership behavior (e.g., Huang, Iun, Liu, \& Gong, 2010); these studies were all excluded in our meta-analysis on the grounds that the use of only one subscale would represent a serious deficiency in the measure of empowering leadership. Citizenship behaviors, included as indicators of contextual performance, could be measured in a variety of ways depending on the contexts of studies. Help behaviors, voice behaviors, and special customer-oriented service behaviors were included as citizenship criteria, because these behaviors conceptually refer to work behaviors beyond the job descriptions. We also coded studies for potential moderators that might explain variation in the effect sizes: gender, industry, nationality (e.g., US vs. other countries), and rating sources (selfrating vs. leader rating) in the performance domain.

\section{Meta-analytic procedures}

Meta-analytic estimates were derived using Schmidt and Hunter's (2015) method. Zeroorder correlations, sample sizes, and reliabilities for predictors and criteria were used to conduct the meta-analysis. The average reliabilities for all study variables are in Table 2. Study correlations were weighted by the sample size to produce a sample-weighted mean correlation, and each correlation was corrected for unreliability of both empowering leadership and the outcome measure. To describe variability in the meta-analytic estimates, we reported $80 \%$ credibility intervals and $95 \%$ confidence intervals around the estimated population correlations. Confidence intervals provide an estimate of the variability around the estimated mean correlation; a 95\% confidence interval excluding zero indicates that one can be $95 \%$ confident 
that the average true score correlation is larger than zero. Credibility intervals provide an estimate of the variability of individual correlations across studies; an $80 \%$ credibility interval excluding zero for a positive average correlation indicates that $90 \%$ of the individual correlations in the meta-analysis were greater than zero (fewer than $10 \%$ are zero or less and a maximum of $10 \%$ lie beyond the upper bound of the interval). Thus, confidence intervals estimate variability in the meta-analytic correlation, whereas credibility intervals estimate variability in the individual correlations across the samples.

Percentage of variance in effect sizes explained by artifacts was also computed using the methods suggested by Schmidt and Hunter (2015). To test for homogeneity in the population effect size estimate, we used Schmidt and Hunter's (2015) 75\% rule. This test is a rule of thumb for determining if the heterogeneity is high enough to be meaningful. The ratio of the estimate of error variance in the population effect size to variance in the observed effect sizes was compared to 0.75 . If this value exceeds 0.75 , the remaining unexplained variance is likely due to uncorrected artifacts in the studies and can be ignored.

\section{Results}

Table 3 presents results of the meta-analyses on the potential effects of empowering leadership on employees' evaluations of leaders ( $\rho=.59$ across all leader evaluation criteria). Empowering leadership was related to positive leader evaluations of trust in the leader $(\rho=.65)$, leader-member exchange $(\rho=.59)$, and perceived leader effectiveness $(\rho=.55)$, supporting hypothesis 1 . Hypothesis 2 , that empowering leadership would be related to the development of employee motivation and resources, was also supported $(\rho=.40$ overall). Empowering leadership was positively related to role clarity $(\rho=.52)$, psychological empowerment $(\rho=.46)$, self-leadership $(\rho=.39)$, goal orientation and work effort $(\rho=.30)$, and self-efficacy and 
organization-based self-esteem (OBSE) $(\rho=.29)$. Hypothesis 3 , that empowering leadership would be related to positive attitudes and emotions, was supported too ( $\rho=.43$ overall); empowering leadership was positively related to job satisfaction $(\rho=.43)$, commitment $(\rho=.40)$, work engagement $(\rho=.45)$, and knowledge sharing $(\rho=.50)$. Hypothesis 4 however, was not supported, because the $95 \%$ confidence interval included the value zero (CI $95 \%$ : $\mathrm{LL}=-.54, \mathrm{UL}=$ .12 ), indicating that empowering leadership did not have significant relationship with negative emotions. Lastly, the results did support hypothesis 5, that empowering leadership would be related to performance ( $\rho=.31$ overall). Specifically, empowering leadership was positively related to creativity and innovative behavior $(\rho=.36)$, contextual performance $(\rho=.33)$, withdrawal behaviors $(\rho=.28)$, and job performance $(\rho=.25)$. Overall, empowering leadership may positively influence evaluations of leaders and the subordinate's motivation factors, work attitudes, and performance, but not the subordinate's emotions.

\section{Tests of moderation}

In an effort to examine whether the results of the meta-analysis were affected by the study design variables, we conducted moderator analyses on potential moderators that were part of the meta-analytic dataset. As can be seen in Table 3, the amount of explained variance in the observed correlations is less $75 \%$, suggesting the presence of moderators based on the $75 \%$ rule (as described above; Schmidt \& Hunter, 2015). We also used the $80 \%$ credibility interval to judge the likelihood and significance of moderators. Many potential moderators could not be analyzed because of a small number of studies in some categories, and thus moderator results should be interpreted as only suggestive (see Table 4, 5, 6, and 7).

First, regarding source of the criterion measure as a moderator, when performance (e.g., creativity, job performance, and contextual performance) was rated by self-reports, a moderate 
positive correlation appeared, from $\rho=.33$ to $\rho=.45$, and the correlations for other-ratings of performance were lower $(\rho=.21$ to $\rho=.31)$. The empowering leadership-contextual performance (e.g., citizenship and deviance behaviors) relation seems to vary the most by rating source. The overall analysis revealed that the effect sizes were stronger for self-reported criteria $(\rho=.42)$ than other-reported criteria $(\rho=.26)$, and the standard deviation of the true score correlation decreased when we considered different source estimates $\left(S D_{\rho}=.09\right.$, compared with $S D_{\rho}=.12$ for the same source), which may be due to common source bias (Table 4).

The second moderator we examined was nation, a surrogate for culture. Thus, we compared the United States and Canada with Asian countries (e.g., South Korea and China) and "other" countries in cases where there were at least two studies conducted in each of these regions. We found that the relationship between empowering leadership and psychological empowerment was $\rho=.51$ in Asian samples, whereas it was $\rho=.41$ in North American samples. Studies using Asian and North American samples yielded the same corrected correlations for job satisfaction $(\rho=.43)$. For commitment and self-concepts (e.g., self-efficacy and OBSE), however, North American samples yielded a corrected correlation greater than Asian samples did ( $\rho=.41$ vs. $\rho=.31$ for commitment; $\rho=.54$ vs. $\rho=.34$ for self-concepts), which is in the direction suggested by the rationale that empowering leadership would have more positive effects in individualistic cultures. The difference was modest, however.

For testing more exploratory moderators, gender and industry were examined mainly because these variables were available in the data rather than for conceptual reasons (see Tables 6 and 7). However, the patterns of results of these moderator analyses were not strong, consistent, or clear. For gender, the largest difference in effect sizes was for evaluations of leaders. Women employees seem to hold more favorable views about empowering leaders than 
men, showing higher correlations for evaluations of leaders $(\rho=.70$ for women vs. $\rho=.49$ for men). Men and women were not different in the strength of the relationships between empowering leadership and the other criteria.

We also compared industry types (samples from service vs samples from manufacturing vs sample from technology). Regarding industry, only the relationship between empowering leadership and employees' evaluations of their leaders varied noticeably. In the service sector, the relationship between empowering leadership and evaluations of leaders was stronger than in the manufacturing sector $(\rho=.75$ vs $\rho=.50)$. There were not enough studies in the technology sector to make comparisons of effects sizes for it with the other sectors.

Finally, we also did some reanalysis to determine the degree to which unpublished studies might be affecting the overall results and conclusions. All studies were either published in journals, were dissertations (2), or were conference presentations (8); in the reanalysis, we removed the dissertations and conference presentations from the data. In the five major categories of outcomes (Table 3), the number of unpublished studies ranged from only 0-6. When we removed these studies and ran the meta-analysis again for the five outcome categories, the results were substantially the same. For three of the five main categories of outcomes, the Mean $\rho$ was unchanged, and for the other two there was a change of only .01 and .02 . We conclude that the inclusion of the unpublished studies did not affect the study's conclusions.

\section{Discussion}

Empowering leadership theoretically links to positive and constructive variables such as job autonomy (e.g., Zhang \& Bartol, 2010) and self-efficacy (e.g., Kim \& Beehr, in pressa) and therefore is expected to promote favorable employee perceptual, attitudinal, motivational and behavioral outcomes. There have been mostly positive results regarding these outcomes, but 
A META-ANALYSIS OF EMPOWERING LEADERSHIP 21

there are exceptions too. Enough studies have now accumulated so that a meta-analysis can aid us in coming to valid conclusions about the quantitative research results overall. Thus, as the first meta-analytic review of empowering leadership, the present study estimated population effect sizes by combining the results of studies on the relations between empowering leader behavior and five outcome domains. Our findings indicated that empowering leadership has positive relationships with evaluations of leaders, employee motivation, work attitudes, and performance, but not with subordinates' emotions. Empowering leadership includes relational-oriented behaviors such as treating employees with respect and showing concern for individual employees through consulting and coaching, thereby creating trusting and supportive atmosphere. These leader behaviors contribute to making strong interpersonal connections with subordinates and eventually trigger higher levels of trust in and satisfaction with their leaders.

Most studies included in the current meta-analysis characterized empowering leadership behaviors as development support by providing continuous learning and development opportunities through leaders' guidance and role modeling, as well as autonomy/motivation support by expressing confidence in subordinates, providing opportunities for subordinates to participate in decision making along with sharing information and encouraging initiative. These characteristics of empowering leadership result in desirable employee attitudes and behaviors. The main reason for this is that from the perspective of motivation theories related to self-control (e.g., self-determination theory, Deci and Ryan, 2000; action regulation theory, Raabe, Frese, \& Beehr, 2007), fulfilling employees’ psychological needs for autonomy (feeling in control), competence, and relatedness (feeling cared for) can raise levels of intrinsic motivation.

Further, empowering leadership behaviors are likely to foster employees' job-related resources such as developmental resources (e.g., feedback and career coaching) and work 
resources (e.g., autonomy and encouragement of the use of skills and competence), which may function not only in achieving work goals but also building more resources (so-called gain spirals; Hobfoll, 2011). These resources also have intrinsic motivational potential by stimulating personal growth and learning. Consequently, employees working for empowering leaders in a resourceful work environment can develop favorable attitudes (e.g., job satisfaction and commitment) and performance behaviors (e.g., citizenship behaviors and creativity). These results are in line with studies suggesting that some form of job resources such as autonomy, social support, feedback, and opportunities to learn made employees hold positive attitudes, thereby becoming more engaged in their jobs and less absent and burned out (Schaufeli, \& Bakker, 2004; Schaufeli, Bakker, \& Van Rhenen, 2009).

Contrary to our expectation, no significant relationship between empowering leadership and negative emotions (e.g., emotional exhaustion or burnout) was found. One possible explanation is that empowering leadership, in its emphasis on freedom and self-management, may leave some employees with greater workloads than they prefer and may therefore induce job-related tension. However, only a few studies examined the link between empowering leader behaviors and undesirable employee emotions, and thus we cannot conclude strongly that empowering leadership plays any role in triggering negative (or positive) emotions. Future research may provide more effect sizes to bolster the strength of any conclusion.

It is also important to note that some effect sizes have little to no variability, while other effect sizes fluctuate and show evidence of heterogeneity (as indicated by the variance explained by artifacts). Specifically, regarding motivation and resources (Table 3), there were stable effects for self-leadership and role clarity $\left(S D_{\rho}\right.$ is less than .05 , and the percentage of variance explained is greater than 75.00). Among the attitudes, work engagement showed instability in effect sizes 
$\left(S D_{\rho}=.20\right)$, which suggests the possibility of moderators. The other three attitudes had .05 to .08 $S D_{\rho}$. Similarly, in the performance domains, withdrawal showed good stability $\left(S D_{\rho}=.03\right)$, but none of the other performance measures were particularly stable (.11 to $\left..12 S D_{\rho}\right)$. We therefore encourage additional research on the relationship between empowering leadership and two categories of outcomes, evaluations of leaders and motivation and resources, especially searching for moderators of their relationships with empowering leadership. This will help us understand specific conditions under which empowering leadership may have stronger effects on these types of employees' outcomes. Taken together, empowering leadership promotes a working environment characterized by a higher degree of autonomy, participation, personal development, and employees' positive psychological states, many of which are theoretically related to intrinsic motivation. Therefore, empowering leadership is likely to result in a host of beneficial outcomes for both individuals and organizations.

We tested four variables for possible moderation: source of the measures, nation (or continent) in which the study was conducted, gender, and industry. For source of ratings and nation, we had some general reasons for the analyses, but for gender and industry, the examination was done simply because there was enough variance in those variables to be worth looking at them. The most straight-forward explanation of the source effects is methodological, that common method variance inflated the effect sizes. We were able test source effects mainly on performance-type outcomes, and common methods (when the subordinate was the source of both the empowering leadership and performance ratings) resulted in stronger effects.

For nation as a moderator, we think that cultural values may play a role, but the primary studies did not measure culture variables, and so we strongly encourage future research to examine specific cultural values as possible moderators of the relationship between empowering 
leadership and outcomes. Overall, the differences we found were between Asian and North American samples. We characterize the differences we found as few, modest, and inconsistent, however, and so we can only offer very tentative interpretations. The Asian samples reported feeling more empowered by the empowering leaders, which may be due to the lesser experience with empowerment in more power-distance and uncertainty-avoidance cultures. That is, experiencing empowering leadership in the Asian samples may have been a greater contrast to the normal situation in Asian than in North American organizations. The experience of greater deviation from the norm thus may have led to reporting more empowerment in the Asian samples. North American samples had more positive organizational commitment and selfconcepts than Asian samples in relation to empowering leadership, however. This is in line with what we would have expected. That is, empowering leadership is seen favorably in lower powerdistance and uncertainty-avoidance cultures, and therefore, the North American employees were more likely to react positively to it by committing to the organization and feeling selfenhancement. It would be logical to propose a mediation model in which empowering leadership results in psychological empowerment, which then leads to outcomes (e.g., commitment, engagement, performance, and careers) (Fong \& Snape, 2015; Kim \& Beehr, 2017a; Raub \& Robert, 2013; Zhang \& Bartol, 2010). The mediation effects might differ by culture, however, with this effect being found in Western cultures (e.g., those with low power distance and uncertainty avoidance values) more than in Eastern cultures (e.g., those with higher power distance and uncertainty avoidance values). We recommend future research on this issue. Employee gender and industry were the other two moderators we considered, and the results for them were modest. For gender, there was only moderation between empowering leadership and evaluations of leaders: Female subordinates evaluated leaders more positively if 
the leader employed empowering behaviors. This means that women think empowering leaders are more effective, more trustworthy, and/or have better relationships with their subordinates than men do. It remains to be discovered by future research why men do not seem to be as favorably impressed by empowering leadership, however. Finally, regarding industry, there were stronger effects sizes between empowering leadership and evaluations of leaders for employees in the service industry than in manufacturing. The nature of the typical jobs in service versus manufacturing companies may explain this. For those in service jobs, often dealing with customers, having the power to make adjustments in their work to please idiosyncratic people may be useful for performing effectively, and therefore supervisors who empower the subordinates are seen as supervising more effectively. In contrast, manufacturing jobs are more likely to deal with standardized, inanimate materials that require less autonomy to adjust one's actions than working with humans (e.g., customers) requires. However, future research is needed in order to determine whether this is the reason for the moderating effects of industry.

\section{Study implications}

The results of current study yield several meaningful implications for both research and practice. As mentioned already, the small number of available studies for some analyses suggests that primary research continue to investigate the links between empowering leadership and many of the outcome variables examined here. As an example, research on the link between empowering leadership and emotions is represented by just three studies. Additionally, some relationships showed substantial variability in magnitude, yet moderator analyses provided by the current study did little to explain this variability. Future research should consider both contextual variables and individual characteristics as possible moderators. For example, empowering leadership may be construed as a source of stress for employees who desire 
structure and have low needs for autonomy. Likewise, it may be that empowering leadership works best for employees who possess the competencies for effective leadership, because empowering leadership is, to a certain extent, describing a transfer of leadership from supervisor to subordinate.

The differential effects of empowering leadership on study outcomes also provides important implications for the mechanisms by which empowering leadership operates. Empowering leadership generally shows strong relations with job attitudes, leader evaluations, and indicators of employee motivation, suggesting that these variables are key mechanisms to the act of empowerment. As noted above, variables like these could be mediators. We note, however, that these potential mediator variables also tend to be highly correlated with each other, and it remains unclear which mediators are most relevant to linking empowerment with performance measures. This issue awaits future research. As an example, does self-efficacy retain a meaningful relationship with empowering leadership and/or performance after the broader construct of psychological empowerment is considered?

The results from this study also provide a firm foundation for comparing the effects of empowering leadership with the effects from other leadership constructs. Such efforts would help establish the value of empowering leadership behaviors over other positive leadership behaviors in the literature. Although research has established a distinction between empowering leadership and transformational leadership through factor analysis (e.g., Pearce et al., 2003), these leadership constructs are each theorized to influence performance by improving employee engagement and job attitudes. Because empowering leadership emphasizes psychological empowerment to a much greater extent than transformational leadership, it may have a greater effect on employee engagement indicators and job attitudes than transformational leadership 
does. Research examining any differential relationships with important work variables is limited, however. Authentic leadership, with its focus on relational transparency and balanced processing, may also share conceptual and empirical overlap with empowering leadership that deserves scrutiny (Gardner, Cogliser, Davis, \& Dickens, 2011).

Implications for applied uses of empowering leadership are also promising. Based on the characteristics of empowering leadership, organizations may benefit from developing empowering leadership programs, given the potential for the mostly positive consequences of having empowering leaders. In order to encourage leaders to engage in empowering leadership, it may be helpful for organizations to consider creating a reward system (e.g., advancement) and/or selection tools for manager-level positions that take into account successful empowering leaders. Developing ways to select managers who are already naturally inclined toward empowering styles could benefit the organization and the people in it, and reinforcing empowering leadership with appropriate rewards would strengthen the effects. For current managers, training and leadership coaching also would be a feasible strategy, both to develop empowering leadership skills and to motivate their use (Ely, Boyce, Nelson, Zaccaro, HernezBroome, \& Whyman, 2010).

Although studies conducting team-level analysis were not included in the current analysis, many of the observed effects with empowering leadership have profound implications for team- and group-level functioning. For example, the positive correlation between empowering leadership and subordinate LMX suggests that empowering leadership can reduce divisions within a group, possibly preventing conflict, improving unit cohesion, and encouraging prosocial and supportive behaviors. Additionally, the positive effect of empowering leadership on subordinate efficacy and self-regulation may also transfer to team-level efficacy and 
regulation. Some existing research supports these suggestions (e.g., Magni \& Maruping, 2013; Srivastava et al., 2006.), but further research is required in order to have greater confidence in these relationships.

\section{Limitations}

In our meta-analysis, some outcome categories had small numbers of studies. This can be attributed partly to empowering leadership being somewhat new to the organizational sciences literature. Relatedly, there were not enough studies with the necessary information for the analysis of many meaningful moderators. As the number of studies increases in future, additional meta-analysis may again be needed to verify the strength of our findings and explore more boundary conditions.

Additionally, most of the studies used nonexperimental cross-sectional designs, making it hard to draw strong causal conclusions. Leader behaviors and employee reactions might affect each other in a bidirectional manner (as is recognized especially in LMX theory; Eisenberger, Shoss, Karagonlar, Gonzalez-Morales, Wickham, \& Buffardi, 2014; Lian, Ferris, Morrison, \& Brown, 2014). For example, subordinates can develop trust with their leader based on the leader's empowering behaviors such as informing, support, and delegation. Leaders can also reciprocate by giving more autonomy and favors to subordinates showing a high level of trust between them. In the first situation, empowering leadership causes subordinate LMX, and in the second situation, LMX with subordinates causes empowering leadership. That is, attitudes and behaviors of the dyadic members become interdependent. Therefore, cross-sectional studies are unable to provide evidence about the direction of the presumed causal relationships.

Lastly, uncovering potential mediators and more moderators of the relationship between empowering leadership and outcomes would be helpful to answer the question of how, why, and 
when empowering leadership affects individual and organizational consequences. Therefore, future research should explore potential mediators and moderators of empowering leadershipoutcomes relationships. This could be done at both the individual and team levels, because as noted earlier, there are currently few studies of empowering leadership at the team level. Theorybuilding is warranted to rationalize how the individual and team-level variables are related to each other.

The effect sizes were similar across global regions, but with a slight suggestion that subordinates in Asian countries may respond better to empowering leadership than employees in North American and European countries. Future cross-cultural research thus is warranted in order to clarify the issue, especially research that examines specific cultural dimensions that are theoretically relevant to the issue of empowering leadership, such as power distance, uncertainty avoidance, or collectivism-individualism. Understanding these relationships is critical for organizations seeking to introduce and encourage empowering leadership, as national or organizational culture could potentially serve to undermine some of the anticipated benefits from empowering leadership. For example, subordinates with strong power distance values may see it as inappropriate to delegate leadership responsibility and power to subordinates. Studies are needed in which such cultural values are measured and their effects tested. Additionally, several Asian countries were included in our analyses. However, there may still exist some meaningful differences among our sample's Asian countries although all of these countries were from East Asia (rather than South Asia, Western Asia, or Russia); future research could address this by examining potential differences within Asia in response to empowering leadership.

Effects were stronger for self-reported criteria than other-reported criteria, and we tentatively interpret this as the effects of common method variance, because leader 
empowerment was also usually self-reported. Further research, varying sources of both the predictor and criteria, should be done to confirm or dispel that interpretation.

\section{Conclusion}

Empowering leadership is a relatively new leadership construct that is attracting empirical attention for understanding its function in today's dynamic work environment. The current meta-analysis shows support for the notion that empowering leadership is overall an effective leadership style for increasing positive employee responses, which can lead to promoting organization effectiveness. The results also suggest that future research may need to explore potential antecedents of empowering leadership so that we can firmly promote ways to increase it, and also moderators to better understand the boundaries conditions for its effects. We hope our study serves as a platform for future theoretical and empirical works on empowering leadership. 
A META-ANALYSIS OF EMPOWERING LEADERSHIP 31

\section{References}

References marked with an asterisk indicate studies included in the meta-analysis.

*Ahearne, M., Mathieu, J., \& Rapp, A. (2005). To empower or not to empower your sales force? An empirical examination of the influence of leadership empowerment behavior on customer satisfaction and performance. Journal of Applied Psychology, 90, 945-955.

*Albrecht, S. L., \& Andreetta, M. (2011). The influence of empowering leadership, empowerment and engagement on affective commitment and turnover intentions in community health service workers: Test of a model. Leadership in Health Services, 24, 228-237.

*Amundsen, S., \& Martinsen, Ø. L. (2014a). Self-other agreement in empowering leadership: Relationships with leader effectiveness and subordinates' job satisfaction and turnover intention. The Leadership Quarterly, 25, 784-800.

*Amundsen, S., \& Martinsen, Ø. L. (2014b). Empowering leadership: Construct clarification, conceptualization, and validation of a new scale. The Leadership Quarterly, 25, 487-511.

*Amundsen, S., \& Martinsen, Ø. L. (2015). Linking empowering leadership to job satisfaction, work effort, and creativity: The role of self-leadership and psychological empowerment. Journal of Leadership \& Organizational Studies, 22, 304-323.

Arnold, J. A., Arad, S., Rhoades, J. A., \& Drasgow, F. (2000). The empowering leadership questionnaire: The construction and validation of a new scale for measuring leader behaviors. Journal of Organizational Behavior, 21, 249-269.

* Audenaert, M., \& Decramer, A. (2016). When empowering leadership fosters creative performance: The role of problem-solving demands and creative personality. Journal of Management \& Organization, 1-15. 
*Auh, S., Menguc, B., \& Jung, Y. S. (2014). Unpacking the relationship between empowering leadership and service-oriented citizenship behaviors: A multilevel approach. Journal of the Academy of Marketing Science, 42, 558-579.

Bakker, A. B., \& Demerouti, E. (2007). The Job demands-resources model: State of the art. Journal of Managerial Psychology, 22, 309-328.

Bandura, A. (1982). Self-efficacy mechanism in human agency. American Psychologist, 37 , $122-147$.

Bandura, A. (1997). Self-efficacy: The exercise of control. New York: Freeman.

Bass, B. M., \& Riggio, R. E. (2006). Transformational leadership. Psychology Press.

*Biemann, T., Kearney, E., \& Marggraf, K. (2015). Empowering leadership and managers' career perceptions: Examining effects at both the individual and the team level. The Leadership Quarterly, 26, 775-789.

*Bobbio, A., Bellan, M., \& Manganelli, A. M. (2012). Empowering leadership, perceived organizational support, trust, and job burnout for nurses: A study in an Italian general hospital. Health Care Management Review, 37, 77-87.

*Boudrias, J. S., Gaudreau, P., Savoie, A., \& Morin, A. J. (2009). Employee empowerment: From managerial practices to employees' behavioral empowerment. Leadership \& Organization Development Journal, 30, 625-638.

Chen, G., Kirkman, B. L., Kanfer, R., Allen, D., \& Rosen, B. (2007). A multilevel study of leadership, empowerment, and performance in teams. Journal of Applied Psychology, 92, $331-346$. 
*Chen, Z., Lam, W., \& Zhong, J. A. (2007). Leader-member exchange and member performance: A new look at individual-level negative feedback-seeking behavior and team-level empowerment climate. Journal of Applied Psychology, 92, 202-212.

*Chen, G., Sharima, P. N., Edinger, S. K., Shapiro, D.L., \& Farh, J. L. (2011). Motivating and demotivating forces in teams: Cross-level influences of empowering leadership and relationship conflict. Journal of Applied Psychology, 96, 541-557.

*Cheong, M., Spain, S. M., Yammarino, F. J., \& Yun, S. (2016). Two faces of empowering leadership: Enabling and burdening. The Leadership Quarterly, 27, 602-616.

Cordery, J. L., Morrison, D., Wright, B. M., \& Wall, T. D. (2010). The impact of autonomy and task uncertainty on team performance: A longitudinal field study. Journal of Organizational Behavior, 31, 240-258.

*Dahinten, V. S., MacPhee, M., Hejazi, S., Laschinger, H., Kazanjian, M., McCutcheon, A., \& O'Brien-Pallas, L. (2014). Testing the effects of an empowerment-based leadership development programme: Part 2-staff outcomes. Journal of Nursing Management, 22, $16-28$.

Deci, E. L., \& Ryan, R. M. (2000). The" what" and" why" of goal pursuits: Human needs and the self-determination of behavior. Psychological Inquiry, 11, 227-268.

Den Hartog, D. N., \& De Hoogh, A. H. (2009). Empowering behaviour and leader fairness and integrity: Studying perceptions of ethical leader behaviour from a levels-of-analysis perspective. European Journal of Work and Organizational Psychology, 18, 199-230.

*Dewettinck, K., \& van Ameijde, M. (2011). Linking leadership empowerment behavior to employee attitudes and behavioural intentions: Testing the mediating role of psychological empowerment. Personnel Review, 40, 284-305. 
Eisenberger, R., Shoss, M. K., Karagonlar, G., Gonzalez-Morales, M. G., Wickham, R. E., \& Buffardi, L. C. (2014). The supervisor POS-LMX-subordinate POS chain: Moderation by reciprocation wariness and supervisor's organizational embodiment. Journal of Organizational Behavior, 35, 635-656.

Ely, K., Boyce, L. A., Nelson, J. K., Zaccaro, S. J., Hernez-Broome, G., \& Whyman, W. (2010). Evaluating leadership coaching: A review and integrated framework. The Leadership Quarterly, 21, 585-599.

*Eze, U., Goh, G., Goh, C., \& Tan, T. (2013). Perspectives of SMEs on knowledge sharing. VINE: The Journal of Information and Knowledge Management Systems 43, 210-236.

Follett, M. P. (1926). The giving of orders. Scientific foundations of business administration (pp.29-37). Reprinted in Shafritz, J. M., \& Ott, J. S. (Eds.), Classics of organizational theory (pp. 150-158). Pacific Grove, CA: Brooks/Cole Publishing Company.

*Fong, K. H., \& Snape, E. (2015). Empowering leadership, psychological empowerment and employee outcomes: Testing a multi-level mediating model. British Journal of Management, 26, 126-138.

*Gao, L., Janssen, O., \& Shi, K. (2011). Leader trust and employee voice: The moderating role of empowering leader behaviors. The Leadership Quarterly, 22, 787-798.

Gardner, W. L., Cogliser, C. C., Davis, K. M., \& Dickens, M. P. (2011). Authentic leadership: A review of the literature and research agenda. Leadership Quarterly, 22, 1120-1145.

*Gkorezis, P. (2016). Principal empowering leadership and teacher innovative behavior: a moderated mediation model. International Journal of Educational Management, 30, 1030-1044. 
Graham, K. A. (2015). Do leaders' hierarchical perceptions matter? A social dominance theory perspective of empowering leadership, abusive supervision, and team performance. Unpublished doctoral dissertation, Drexel University, Philadelphia.

Griffin, M.A., Neal, A., \& Parker, S.K. (2007). A new model of work role performance: Positive behavior in uncertain and interdependent contexts. Academy of Management Journal, 50, $327-347$.

Günzel-Jensen, F., Jain, A. K., \& Kjeldsen, A. M. (2016). Distributed leadership in health care: The role of formal leadership styles and organizational efficacy. Leadership, 1-24.

Hackman, J. R., \& Oldham, G. R. (1980). Work redesign. Reading, MA: Addison-Wesley. *Harris, T. B., Li, N., Boswell, W. R., Zhang, X., \& Xie, Z. (2014). Getting what's new from newcomers: Empowering leadership, creativity, and adjustment in the socialization context. Personnel Psychology, 67, 567-604.

*Hassan, S., Mahsud, R., Yukl, G., \& Prussia, G. E. (2013). Ethical and empowering leadership and leader effectiveness. Journal of Managerial Psychology, 28, 133-146.

Hobfoll, S. E. (2011). Conservation of resource caravans and engaged settings. Journal of Occupational and Organizational Psychology, 84, 116-122.

Hofstede, G. (2001). Culture's consequences: Comparing values, behaviors, institutions, and organizations across nations. Thousand Oaks, CA: Sage.

Hon, A. H., \& Chan, W. W. (2013). Team creative performance the roles of empowering leadership, Creative-related motivation, and task interdependence. Cornell Hospitality Quarterly, 54, 199-210. 
Huang, X., Iun, J., Liu, A., \& Gong, Y. (2010). Does participative leadership enhance work performance by inducing empowerment or trust? The differential effects on managerial and non-managerial subordinates. Journal of Organizational Behavior, 31, 122-143.

*Humborstad, S. I. W., \& Giessner, S. R. (2015). The thin line between empowering and laissezfaire leadership: An expectancy-match perspective. Journal of Management, doi: 0149206315574597

*Humborstad, S. I. W., Nerstad, C. G., \& Dysvik, A. (2014). Empowering leadership, employee goal orientations and work performance: A competing hypothesis approach. Personnel Review, 43, 246-271.

Javidan, M., Dorfman, P. W., De Luque, M. S., \& House, R. J. (2006). In the eye of the beholder: Cross cultural lessons in leadership from Project GLOBE. The Academy of Management Perspectives, 20, 67-90.

*Jeong, I., Gong, Y., \& Ju, S. (2016). Relationships among incremental belief, cognitive flexibility, and innovative behavior. Paper presented at the annual meeting of the Academy of Management Annual Meeting, Anaheim, CA, USA.

Kahn, R. L., Wolfe, D. M., Quinn, R. P., Snoek, J. D., \& Rosenthal, R. A. (1964). Organizational stress: Studies in role conflict and ambiguity. New York: Wiley.

*Kim, M., \& Beehr, T. A. (2016a). Psychological states linking empowering leadership to follower behaviors. Paper presented at the annual meeting of the Academy of Management Annual Meeting, Anaheim, CA, USA.

*Kim, M., \& Beehr, T. A. (2016b). The mediating role of psychological ownership in the links between empowering leadership and subordinate behaviors. Paper presented at the annual meeting of the Association for Psychological Science, Chicago, IL: USA. 
*Kim, M., \& Beehr, T. A. (in pressa). Self-efficacy and psychological ownership mediate the effects of empowering leadership on both good and bad employee behaviors. Journal of Leadership \& Organizational Studies, $\underline{10.1177 / 1548051817702078}$

Kim, M., \& Beehr, T. A. (in pressb). Can empowering leaders affect subordinates' well-being and careers because they encourage subordinates' job crafting behaviors?" Journal of Leadership \& Organizational Studies, $\underline{10.1177 / 1548051817727702}$

*Kim, M., \& Beehr, T. A. (2017a). Directing our own careers, but getting help from empowering leaders. Career Development International, 22, 300-317.

Kim, M., \& Beehr, T. A. (2017b). Organization-based self-esteem and meaningful work mediate effects of empowering leadership on employee behavior and well-being. Paper presented at the annual meeting of the Academy of Management, Atlanta, GA.

Kirkman, B. L., Chen, G., Farh, J.-L., Chen, Z. X., \& Lowe, K. B. (2009). Individual power distance orientation and follower reactions to transformational leaders: A cross-level, cross-cultural examination. Academy of Management Journal, 52, 744-764.

*Konczak, L. J., Stelly, D. J., \& Trusty, M. L. (2000). Defining and measuring empowering leader behaviors: Development of an upward feedback instrument. Educational and Psychological Measurement, 60, 301-313.

Koopman, P. L., \& Wierdsma, A. F. M. (1998). Participative management. In P. J. D. Doentu, H. Thierry, \& C. J. de-Wolf (Eds.), Personnel psychology: Handbook of work and organizational psychology (Vol. 3, pp. 297-324). Hove, U.K.: Psychology Press/Erlbaum. 
*Kwak, W. J. (2011). Multi-level investigation of empowering leadership, leader-member exchange, and subordinate empowerment. Unpublished doctoral dissertation, Purdue University, Indiana.

Langfred, C. W., \& Moye, N. A. (2004). Effects of task autonomy on performance: an extended model considering motivational, informational, and structural mechanisms. Journal of Applied Psychology, 89, 934-945.

Leach, D. J., Wall, T. D., \& Jackson, P. R. (2003). The effect of empowerment on job knowledge: An empirical test involving operators of complex technology. Journal of Occupational and Organizational Psychology, 76, 27-52.

Leana, C. R. (1987). Power relinquishment versus power sharing: Theoretical clarification and empirical comparison of delegation and participation. Journal of Applied Psychology, 72, 228-233.

*Lee, M. C. C., Idris, M. A., \& Delfabbro, P. H. (2017). The linkages between hierarchical culture and empowering leadership and their effects on employees' work engagement: Work meaningfulness as a mediator. International Journal of Stress Management, 24, $392-415$.

*Lee, S., Cheong, M., Kim, M., \& Yun, S. (2016). Never too much? The curvilinear relationship between empowering leadership and task performance. Group \& Organization Management, published early online 2016.

*Li, M., Liu, W., Han, Y., \& Zhang, P. (2016). Linking empowering leadership and changeoriented organizational citizenship behavior: The role of thriving at work and autonomy orientation. Journal of Organizational Change Management, 29, 732-750. 
*Li, N., Chiaburu, D. S., \& Kirkman, B. L. (2014). Cross-level influences of empowering leadership on citizenship behavior organizational support climate as a double-edged sword. Journal of Management, doi:10.1177/0149206314546193

*Li, P., \& Chen, S. (2016). Linking perspective taking and employee creative self-efficacy: The role of an involved leader. Paper presented at the annual meeting of the Academy of Management Annual Meeting, Anaheim, CA, USA.

Li, S. L., Huo, Y., \& Long, L. R. (2015). Chinese traditionality matters: Effects of differentiated empowering leadership on followers' trust in leaders and work outcomes. Journal of Business Ethics, 1-13.

Lian, H., Ferris, D. L., \& Brown, D. J. (2012). Does power distance exacerbate or mitigate the effects of abusive supervision? It depends on the outcome. Journal of Applied Psychology, 97, 107-123.

Lian, H., Ferris, D. L., Morrison, R., \& Brown, D. J. (2014). Blame it on the supervisor or the subordinate? Reciprocal relations between abusive supervision and organizational deviance. Journal of Applied Psychology, 99, 651-664.

Likert, R. (1961). New patterns of management. New York, NY: McGraw-Hill.

Lorinkova, N. M., Pearsall, M. J., \& Sims, H. P. (2013). Examining the differential longitudinal performance of directive versus empowering leadership in teams. Academy of Management Journal, 56, 573-596.

*Lorinkova, N. M., \& Perry, S. J. (2014). When is empowerment effective? The role of leaderleader exchange in empowering leadership, cynicism, and time theft. Journal of Management, doi: 10.1177/0149206314560411 
*Luo, W., Liu, D., \& Zhang, K. (2016). A motivational framework of followership behavior: Scale development and nomological network. Paper presented at the annual meeting of the Academy of Management Annual Meeting, Anaheim, CA, USA.

Magni, M., \& Maruping, L. M. (2013). Sink or swim: Empowering leadership and overload in teams' ability to deal with the unexpected. Human Resource Management, 52, 715-739.

Manz, C. C., \& Sims Jr, H. P. (1987). Leading workers to lead themselves: The external leadership of self-managing work teams. Administrative Science Quarterly, 32, 106-129.

*Martin, S. L., Liao, H., \& Campbell, E. M. (2013). Directive versus empowering leadership: A field experiment comparing impacts on task proficiency and proactivity. Academy of Management Journal, 56, 1372-1395.

*Martínez-Córcoles, M., Gracia, F. J., Tomás, I., \& Peiró, J. M. (2014). Strengthening safety compliance in nuclear power operations: A role-based approach. Risk Analysis, 34, 1257 1269.

Maynard, M. T., Gilson, L. L., \& Mathieu, J. E. (2012). Empowerment—fad or fab? A multilevel review of the past two decades of research. Journal of Management, 38, 12311281.

Maynard, M. T., Luciano, M. M., D’Innocenzo, L., Mathieu, J. E., \& Dean, M. D. (2014). Modeling time-lagged reciprocal psychological empowerment-performance relationships. Journal of Applied Psychology, 99, 1244-1253.

*Namasivayam, K., Guchait, P., \& Lei, P. (2014). The influence of leader empowering behaviors and employee psychological empowerment on customer satisfaction. International Journal of Contemporary Hospitality Management, 26, 69-84. 
Pearce, C. L., Sims Jr, H. P., Cox, J. F., Ball, G., Schnell, E., Smith, K. A., \& Trevino, L. (2003). Transactors, transformers and beyond: A multi-method development of a theoretical typology of leadership. Journal of Management Development, 22, 273-307.

Pierce, J. L., Gardner, D. G., Cummings, L. L., \& Dunham, R. B. (1989). Organization-based self-esteem: Construct definition, measurement, and validation. Academy of Management Journal, 32, 622-648.

Raabe, B., Frese, M., \& Beehr, T. A. (2007). Action regulation theory and career-self management. Journal of Vocational Behavior, 70, 297-311.

*Randolph, W. A., \& Kemery, E. R. (2011). Managerial use of power bases in a model of managerial empowerment practices and employee psychological empowerment. Journal of Leadership \& Organizational Studies, 18, 95-106.

*Raub, S., \& Robert, C. (2010). Differential effects of empowering leadership on in-role and extra-role employee behaviors: Exploring the role of psychological empowerment and power values. Human Relations, 63, 1743-1770.

*Raub, S., \& Robert, C. (2013). Empowerment, organizational commitment, and voice behavior in the hospitality industry evidence from a multinational sample. Cornell Hospitality Quarterly, 54, 136-148.

Schaufeli, W. B., \& Bakker, A. B. (2004). Job demands, job resources, and their relationship with burnout and engagement: A multi-sample study. Journal of Organizational Behavior, 25, 293-315.

Schaufeli, W. B., Bakker, A. B., \& Van Rhenen, W. (2009). How changes in job demands and resources predict burnout, work engagement, and sickness absenteeism. Journal of Organizational Behavior, 30, 893-917. 
Schmidt, F. L., \& Hunter, J. E. (2015). Methods of meta-analysis: Correcting error and bias in research findings ( $3^{\text {rd }}$ ed.). Thousand Oaks, CA: Sage.

Seibert, S. E., Silver, S. R., \& Randolph, W. A. (2004). Taking empowerment to the next level: A multiple-level model of empowerment, performance, and satisfaction. Academy of Management Journal, 47, 332-349.

Seibert, S. E., Wang, G., \& Courtright, S. H. (2011). Antecedents and consequences of psychological and team empowerment in organizations: A meta-analytic review. Journal of Applied Psychology, 96, 981-1003.

Sharma, P. N., \& Kirkman, B. L. (2015). Leveraging leaders a literature review and future lines of inquiry for empowering leadership research. Group \& Organization Management, 40, 193-237.

Sparrowe, R. T., \& Liden, R. C. (1997). Process and structure in leader-member exchange. Academy of Management Review, 22, 522-552.

Spreitzer, G. M. (1995). Psychological empowerment in the workplace: Dimensions, measurement, and validation. Academy of Management Journal, 38, 1442-1465.

Spreitzer, G. M. (2008). Taking stock: A review of more than twenty years of research on empowerment at work. In J. Barling \& C. L. Cooper (Eds.), Handbook of organizational behavior (pp. 54-72). Thousand Oaks, CA: Sage.

Srivastava, A., Bartol, K. M., \& Locke, E. A. (2006). Empowering leadership in management teams: Effects on knowledge sharing, efficacy and performance. Academy of Management Journal, 49, 1239-1251. 
*Sumpter, D. M., Gibson, C. B., \& Porath, C. (2016). Act expediently, with autonomy: Vicarious learning, empowered behaviors, and performance. Journal of Business and Psychology, $1-15$.

*Tekleab, A. G., Sims Jr, H. P., Yun, S., Tesluk, P. E., \& Cox, J. (2008). Are we on the same page? Effects of self-awareness of empowering and transformational leadership. Journal of Leadership \& Organizational Studies, 14, 185-202.

Thomas, K. W., \& Velthouse, B. A. (1990). Cognitive elements of empowerment: An "interpretive" model of intrinsic task motivation. Academy of Management Review, 15, $666-681$.

*Tong, D. Y. K., Rasiah, D., Tong, X. F., \& Lai, K. P. (2015). Leadership empowerment behaviour on safety officer and safety teamwork in manufacturing industry. Safety science, 72, 190-198.

*Tuckey, M. R., Bakker, A. B., \& Dollard, M. F. (2012). Empowering leaders optimize working conditions for engagement: A multilevel study. Journal of Occupational Health Psychology, 17, 15-27.

Tung, H. L., \& Chang, Y. H. (2011). Effects of empowering leadership on performance in management team: Mediating effects of knowledge sharing and team cohesion. Journal of Chinese Human Resources Management, 2, 43-60.

*Vecchio, R. P., Justin, J. E., \& Pearce, C. L. (2010). Empowering leadership: An examination of mediating mechanisms within a hierarchical structure. The Leadership Quarterly, 21, $530-542$.

Vroom, V. H., \& Yetton, P. W. (1973). Leadership and decision-making. Pittsburgh, PA: University of Pittsburgh Press. 
*Wallace, J. C., Johnson, P. D., Mathe, K., \& Paul, J. (2011). Structural and psychological empowerment climates, performance, and the moderating role of shared felt accountability: A managerial perspective. Journal of Applied Psychology, 96, 840-850.

Xanthopoulou, D., Bakker, A. B., Demerouti, E., \& Schaufeli, W. B. (2007). The role of personal resources in the job demands-resources model. International Journal of Stress Management, 14, 121-141.

*Xue, Y., Bradley, J., \& Liang, H. (2011). Team climate, empowering leadership, and knowledge sharing. Journal of Knowledge Management, 15, 299-312.

*Yagil, D. (2002). The relationship of customer satisfaction and service workers' perceived control: Examination of three models. International Journal of Service Industry Management, 13, 382-398.

*Yoon, H. J. (2012). Predicting employee voice behavior: An exploration of the roles of empowering leadership, power distance, organizational learning capability, and sense of empowerment in Korean organizations. Unpublished doctoral dissertation, University of Minnesota, Minneapolis.

Yukl, G., \& Fu, P. P. (1999). Determinants of delegation and consultation by managers. Journal of Organizational Behavior, 20, 219-232.

*Zhang, X., \& Bartol, K. M. (2010). Linking empowering leadership and employee creativity: The influence of psychological empowerment, intrinsic motivation, and creative process engagement. Academy of Management Journal, 53, 107-128.

*Zhang, X., \& Zhou, J. (2014). Empowering leadership, uncertainty avoidance, trust, and employee creativity: Interaction effects and a mediating mechanism. Organizational Behavior and Human Decision Processes, 124, 150-164. 
Table 1

Categories Used in the Meta-Analysis

\begin{tabular}{|c|c|}
\hline Category & Sample concepts \\
\hline Evaluations of Leaders & $\begin{array}{l}\text { Trust in the leader, leader-member exchange, } \\
\text { perceived leader effectiveness }\end{array}$ \\
\hline \multicolumn{2}{|l|}{ Motivation \& Resources } \\
\hline Psychological Empowerment & $\begin{array}{l}\text { Psychological empowerment (impact, } \\
\text { meaningfulness, competence, and self- } \\
\text { determination) }\end{array}$ \\
\hline Self-Leadership & $\begin{array}{l}\text { Self-leadership (achievement orientation and self- } \\
\text { regulation) }\end{array}$ \\
\hline Self-Efficacy & $\begin{array}{l}\text { Generalized self-efficacy, career self-efficacy, } \\
\text { creative self-efficacy, organization-based self- } \\
\text { esteem }\end{array}$ \\
\hline Goal Orientation & Goal Orientation, work effort \\
\hline Role Clarity & Role clarity, role conflict \\
\hline \multicolumn{2}{|l|}{ Attitudes } \\
\hline Job Satisfaction & Job satisfaction, career satisfaction \\
\hline Commitment & $\begin{array}{l}\text { Affective commitment, organizational commitment, } \\
\text { career commitment }\end{array}$ \\
\hline Work Engagement & $\begin{array}{l}\text { Work engagement (vigor, dedication, and } \\
\text { absorption) }\end{array}$ \\
\hline knowledge sharing & attitudes towards knowledge sharing \\
\hline Emotions & Tension, burnout, cynicism \\
\hline \multicolumn{2}{|l|}{ Performance } \\
\hline Creativity & Innovative behavior, creative performance \\
\hline Job Performance & $\begin{array}{l}\text { Job performance, task proficiency, customer } \\
\text { satisfaction }\end{array}$ \\
\hline Contextual Performance & $\begin{array}{l}\text { OCBI, OCBO, helping behavior, voice behavior, } \\
\text { change-oriented organizational citizenship behavior, } \\
\text { taking charge behavior, proactive behaviors, } \\
\text { interpersonal deviance, organizational deviance, } \\
\text { time theft behaviors }\end{array}$ \\
\hline Withdrawal & $\begin{array}{l}\text { Turnover intentions, intention to quit, intention to } \\
\text { stay, absenteeism }\end{array}$ \\
\hline
\end{tabular}


Table 2

Average Internal Consistency Reliabilities for All Study Variables

\begin{tabular}{lc}
\hline Variable & Reliability $(\alpha)$ \\
\hline Empowering leadership & .91 \\
Trust in leader & .86 \\
Leader-member exchange & .90 \\
Perceived leader effectiveness & .93 \\
Psychological empowerment & .84 \\
Self-leadership & .87 \\
Self-efficacy \& OBSE & .85 \\
Goal orientation \& Work effort & .84 \\
Role clarity & .83 \\
Job satisfaction & .84 \\
Commitment & .86 \\
Work engagement & .92 \\
Knowledge sharing & .86 \\
Emotional exhaustion \&Tension \& Cynicism & .84 \\
Creativity \& Innovative behaviors & .84 \\
Job performance & .88 \\
Wontextual performance & .89 \\
\hline
\end{tabular}


Table 3

Relationships of Empowering Leadership with Employee Outcomes

\begin{tabular}{|c|c|c|c|c|c|c|c|c|}
\hline Outcome & $k$ & $N$ & Mean $r$ & Mean $\rho$ & $S D_{\rho}$ & $\begin{array}{l}\% \text { of variance } \\
\text { accounted for }\end{array}$ & $80 \% \mathrm{CV}$ & $95 \% \mathrm{CI}$ \\
\hline Evaluations of Leaders & 13 & 2845 & .53 & .59 & .17 & 9.32 & $.37, .81$ & $.49, .69$ \\
\hline Trust in the leader & 5 & 1225 & .57 & .65 & .11 & 16.35 & $.51, .79$ & $.54, .76$ \\
\hline Leader-Member Exchange & 5 & 1094 & .54 & .59 & .16 & 10.22 & $.39, .79$ & $.45, .74$ \\
\hline Perceived Leader Effectiveness & 4 & 785 & .49 & .55 & .22 & 6.73 & $.27, .83$ & $.33, .77$ \\
\hline Motivation \& Resources & 39 & 13525 & .35 & .40 & .15 & 11.52 & $.21, .59$ & $.35, .45$ \\
\hline Self-Leadership & 3 & 612 & .35 & .39 & .04 & 78.65 & $.34, .43$ & $.30, .48$ \\
\hline Self-Efficacy \& OBSE & 9 & 4479 & .24 & .29 & .17 & 8.07 & $.07, .50$ & $.17, .40$ \\
\hline Goal Orientation \& Work effort & 3 & 1025 & .26 & .30 & .05 & 59.75 & $.24, .36$ & $.22, .39$ \\
\hline Psychological Empowerment & 25 & 7355 & .41 & .46 & .11 & 19.94 & $.32, .60$ & $.41, .51$ \\
\hline Role Clarity & 3 & 813 & .46 & .52 & .00 & 100.00 & $.52, .52$ & $.48, .57$ \\
\hline
\end{tabular}


Table 3

Continued

\begin{tabular}{|c|c|c|c|c|c|c|c|c|}
\hline Outcome & $k$ & $N$ & Mean $r$ & Mean $\rho$ & $S D_{\rho}$ & $\begin{array}{l}\% \text { of variance } \\
\text { accounted for }\end{array}$ & $80 \% \mathrm{CV}$ & $95 \% \mathrm{CI}$ \\
\hline Attitudes & 23 & 8507 & .38 & .43 & .08 & 25.96 & $.33, .54$ & $.39, .48$ \\
\hline Satisfaction & 12 & 5196 & .38 & .43 & .05 & 49.08 & $.37, .50$ & $.40, .47$ \\
\hline Commitment & 12 & 3148 & .36 & .40 & .08 & 34.63 & $.30, .51$ & $.35, .46$ \\
\hline Work Engagement & 4 & 1096 & .40 & .45 & .20 & 7.24 & $.19, .71$ & $.25, .66$ \\
\hline Knowledge Sharing & 2 & 684 & .44 & .50 & .08 & 26.58 & $.40, .61$ & $.37, .64$ \\
\hline Emotions & 3 & 660 & -.19 & -.21 & .28 & 6.69 & $-.57, .15$ & $-.54, .12$ \\
\hline $\begin{array}{l}\text { Emotional Exhaustion \& } \\
\text { Tension \& Cynicism }\end{array}$ & 3 & 660 & -.19 & -.21 & .28 & 6.69 & $-.57, .15$ & $-.54, .12$ \\
\hline Performance & 33 & 9455 & .29 & .31 & .12 & 20.55 & $.16, .46$ & $.27, .36$ \\
\hline $\begin{array}{l}\text { Creativity \& Innovative } \\
\text { Behavior }\end{array}$ & 10 & 2332 & .33 & .36 & .11 & 24.72 & $.22, .50$ & $.28, .44$ \\
\hline Job Performance & 12 & 3355 & .22 & .25 & .11 & 23.87 & $.10, .39$ & $.17, .32$ \\
\hline Contextual Performance & 13 & 5024 & .30 & .33 & .12 & 14.44 & $.17, .49$ & $.25, .40$ \\
\hline Withdrawal & 6 & 1605 & .25 & .28 & .03 & 82.95 & $.25,32$ & $.23, .34$ \\
\hline
\end{tabular}

Note. $k=$ number of samples; $N=$ total sample size; Mean $r=$ average weighted correlation coefficient; Mean $\rho=$ average weighted correlation coefficient corrected for unreliability in the dependent and independent variables; $S D_{\rho}=$ standard deviation of Mean $\rho$; \% of variance accounted for refers to the variance explained by artifacts; $80 \%$ Credibility and 95\% Confidence Interval based around Mean $\rho$. Withdrawals, deviance, and time theft behaviors were reverse-coded. 
A META-ANALYSIS OF EMPOWERING LEADERSHIP 49

Table 4

Categorical Moderator Analyses for Rating Source

\begin{tabular}{|c|c|c|c|c|c|c|c|c|c|}
\hline Variable & Rating Source & $k$ & $N$ & Mean $r$ & Mean $\rho$ & $S D_{\rho}$ & $\begin{array}{l}\% \text { of variance } \\
\text { accounted for }\end{array}$ & $80 \% \mathrm{CV}$ & $95 \% \mathrm{CI}$ \\
\hline \multirow{2}{*}{ Overall } & Leader & 19 & 5614 & .24 & .26 & .09 & 29.18 & $.14, .38$ & $.21, .31$ \\
\hline & Self & 9 & 2622 & .39 & .42 & .12 & 17.73 & $.27, .57$ & $.34, .51$ \\
\hline $\begin{array}{l}\text { Creativity and } \\
\text { Innovative }\end{array}$ & Leader & 6 & 1542 & .29 & .31 & .12 & 22.06 & $.16, .46$ & $.21, .42$ \\
\hline Behavior & Self & 4 & 790 & .42 & .45 & .00 & 100.00 & $.45, .45$ & $.40, .49$ \\
\hline \multirow{2}{*}{ Job Performance } & $\begin{array}{l}\text { Leader \& } \\
\text { Customer }\end{array}$ & 10 & 2401 & .19 & .21 & .09 & 37.16 & $.09, .33$ & $.14, .28$ \\
\hline & Self & 2 & 954 & .30 & .33 & .11 & 13.61 & $.19, .48$ & $.16, .51$ \\
\hline \multirow{2}{*}{$\begin{array}{l}\text { Contextual } \\
\text { Performance }\end{array}$} & Leader & 8 & 3192 & .25 & .27 & .06 & 42.12 & $.19, .35$ & $.21, .33$ \\
\hline & Self & 5 & 1832 & .39 & .42 & .15 & 10.10 & $.24, .61$ & $.29, .56$ \\
\hline
\end{tabular}


Table 5

Categorical Moderator Analyses for Country

\begin{tabular}{|c|c|c|c|c|c|c|c|c|c|}
\hline Variable & Country & $k$ & $N$ & Mean $r$ & Mean $\rho$ & $S D_{\rho}$ & $\begin{array}{l}\% \text { of variance } \\
\text { accounted for }\end{array}$ & $80 \% \mathrm{CV}$ & $95 \% \mathrm{CI}$ \\
\hline & North America & 13 & 3231 & .39 & .44 & .13 & 18.23 & $.28, .60$ & $.36, .52$ \\
\hline \multirow[t]{2}{*}{ Overall } & Asia & 13 & 3801 & .40 & .46 & .14 & 14.31 & $.28, .63$ & $.38, .54$ \\
\hline & Other & 8 & 4802 & .27 & .32 & .16 & 7.05 & $.12, .52$ & $.20, .43$ \\
\hline \multirow[t]{3}{*}{$\begin{array}{l}\text { Psychological } \\
\text { Empowerment }\end{array}$} & US and Canada & 10 & 2452 & .37 & .41 & .08 & 35.60 & $.30, .51$ & $.34, .47$ \\
\hline & Asia $^{1}$ & 8 & 2594 & .45 & .51 & .12 & 14.70 & $.35, .67$ & $.42, .60$ \\
\hline & Other $^{1}$ & 7 & 2309 & .41 & .46 & .09 & 23.39 & $.34, .58$ & $.38, .54$ \\
\hline \multirow[t]{3}{*}{$\begin{array}{l}\text { Self-Efficacy } \\
\text { and OBSE }\end{array}$} & US and Canada & 3 & 779 & .46 & .54 & .18 & 8.27 & $.31, .77$ & $.32, .75$ \\
\hline & $\mathrm{Asia}^{2}$ & 5 & 1207 & .30 & .34 & .08 & 40.75 & $.24, .44$ & $.25, .43$ \\
\hline & Other $^{2}$ & 1 & \multicolumn{7}{|c|}{ Not Available } \\
\hline
\end{tabular}

Note. Asia ${ }^{1}$ included South Korea, China, Hong Kong, and Malaysia. Other ${ }^{1}$ included Middle Eastern (e.g., Egypt, United Arab Emirates), Norway, and Belgium. Asia ${ }^{2}$ included South Korea and China. Other ${ }^{2}$ included German. 
Table 5

Continued

\begin{tabular}{|c|c|c|c|c|c|c|c|c|c|}
\hline Variable & Country & $k$ & $N$ & Mean $r$ & Mean $\rho$ & $S D_{\rho}$ & $\begin{array}{l}\% \text { of variance } \\
\text { accounted for }\end{array}$ & $80 \% \mathrm{CV}$ & $95 \% \mathrm{CI}$ \\
\hline & North America & 8 & 1785 & .37 & .41 & .05 & 58.00 & $.34, .48$ & $.35, .47$ \\
\hline \multirow[t]{2}{*}{ Overall } & Asia & 4 & 1006 & .34 & .41 & .07 & 50.22 & $.32, .49$ & $.31, .50$ \\
\hline & Other & 6 & 4075 & .39 & .44 & .02 & 76.30 & $.41, .46$ & $.40, .57$ \\
\hline \multirow[t]{3}{*}{ Job Satisfaction } & US and Canada & 5 & 1011 & .40 & .43 & .07 & 48.44 & $.35, .52$ & $.35, .51$ \\
\hline & $\operatorname{Asia}^{1}$ & 2 & 750 & .35 & .43 & .07 & 38.80 & $.34, .52$ & $.31, .55$ \\
\hline & Other $^{1}$ & 5 & 3435 & .38 & .44 & .03 & 55.88 & $.39, .48$ & $.39, .48$ \\
\hline \multirow[t]{3}{*}{ Commitment } & US and Canada & 7 & 1606 & .37 & .41 & .08 & 40.83 & $.31, .51$ & $.34, .48$ \\
\hline & $\mathrm{Asia}^{2}$ & 3 & 522 & .26 & .31 & .00 & 100 & $.31, .31$ & $.22, .40$ \\
\hline & Other $^{2}$ & 2 & 1020 & .40 & .43 & .08 & 18.92 & $.33, .54$ & $.30, .56$ \\
\hline
\end{tabular}

Note. Asia ${ }^{1}$ included South Korea and Hong Kong. Asia ${ }^{2}$ included China and Hong Kong. Other ${ }^{1}$ included German, Norway, and Belgium. Other ${ }^{2}$ included Belgium and Middle Eastern. 
A META-ANALYSIS OF EMPOWERING LEADERSHIP 52

Table 6

Categorical Moderator Analyses for Gender

\begin{tabular}{|c|c|c|c|c|c|c|c|c|c|}
\hline Variable & Gender & $k$ & $N$ & Mean $r$ & Mean $\rho$ & $S D_{\rho}$ & $\begin{array}{l}\% \text { of variance } \\
\text { accounted for }\end{array}$ & $80 \% \mathrm{CV}$ & $95 \% \mathrm{CI}$ \\
\hline \multirow{2}{*}{$\begin{array}{l}\text { Evaluations of } \\
\text { Leaders }\end{array}$} & Male & 7 & 1491 & .43 & .49 & .17 & 12.92 & $.28, .70$ & $.36, .62$ \\
\hline & Female & 4 & 1004 & .64 & .70 & .12 & 10.53 & $.54, .85$ & $.57, .82$ \\
\hline \multirow{2}{*}{$\begin{array}{l}\text { Motivation \& } \\
\text { Resources }\end{array}$} & Male & 17 & 5315 & .41 & .46 & .13 & 14.97 & $.30, .62$ & $.40, .53$ \\
\hline & Female & 14 & 3647 & .40 & .46 & .12 & 19.14 & $.30, .61$ & $.39, .53$ \\
\hline \multirow{2}{*}{ Attitudes } & Male & 7 & 2624 & .38 & .44 & .07 & 36.48 & $.35, .52$ & $.37, .50$ \\
\hline & Female & 11 & 2533 & .42 & .46 & .11 & 22.82 & $.32, .60$ & $.39, .53$ \\
\hline \multirow{2}{*}{ Performance } & Male & 20 & 5854 & .29 & .32 & .13 & 16.60 & $.15, .49$ & $.26, .38$ \\
\hline & Female & 10 & 2460 & .25 & .28 & .07 & 49.41 & $.19, .36$ & $.22, .34$ \\
\hline
\end{tabular}


Table 7

Categorical Moderator Analyses for Industry

\begin{tabular}{|c|c|c|c|c|c|c|c|c|c|}
\hline Variable & Industry & $k$ & $N$ & Mean $r$ & Mean $\rho$ & $S D_{\rho}$ & $\begin{array}{l}\% \text { of variance } \\
\text { accounted for }\end{array}$ & $80 \% \mathrm{CV}$ & $95 \% \mathrm{CI}$ \\
\hline \multirow{2}{*}{$\begin{array}{l}\text { Evaluations of } \\
\text { Leaders }\end{array}$} & Service & 2 & 587 & .69 & .75 & .04 & 38.54 & $.70, .81$ & $.68, .83$ \\
\hline & Manufacturing & 7 & 1376 & .43 & .50 & .17 & 12.75 & $.27, .72$ & $.36, .63$ \\
\hline \multirow{4}{*}{$\begin{array}{l}\text { Motivation \& } \\
\text { Resources }\end{array}$} & Technology & 1 & \multicolumn{7}{|c|}{ Not Available } \\
\hline & Service & 13 & 4481 & .38 & .43 & .05 & 52.71 & $.36, .49$ & $.39, .46$ \\
\hline & Manufacturing & 13 & 5848 & .28 & .33 & .17 & 8.43 & $.12, .55$ & $.24, .43$ \\
\hline & Technology & 3 & 856 & .39 & .46 & .20 & 8.11 & $.20, .71$ & $.22, .69$ \\
\hline \multirow{2}{*}{ Attitudes } & Service & 10 & 2905 & .36 & .40 & .07 & 37.57 & $.30, .49$ & $.34, .46$ \\
\hline & Manufacturing & 4 & 3344 & .38 & .44 & .05 & 29.55 & $.37, .51$ & $.38, .50$ \\
\hline \multirow{4}{*}{ Performance } & Technology & 0 & \multicolumn{7}{|c|}{ Not Available } \\
\hline & Service & 11 & 3756 & .28 & .31 & .07 & 36.88 & $.22, .41$ & $.26, .37$ \\
\hline & Manufacturing & 8 & 2249 & .33 & .36 & .13 & 16.70 & $.19, .52$ & $.26, .46$ \\
\hline & Technology & 4 & 882 & .24 & .26 & .00 & 100 & $.26, .26$ & $.20, .33$ \\
\hline
\end{tabular}




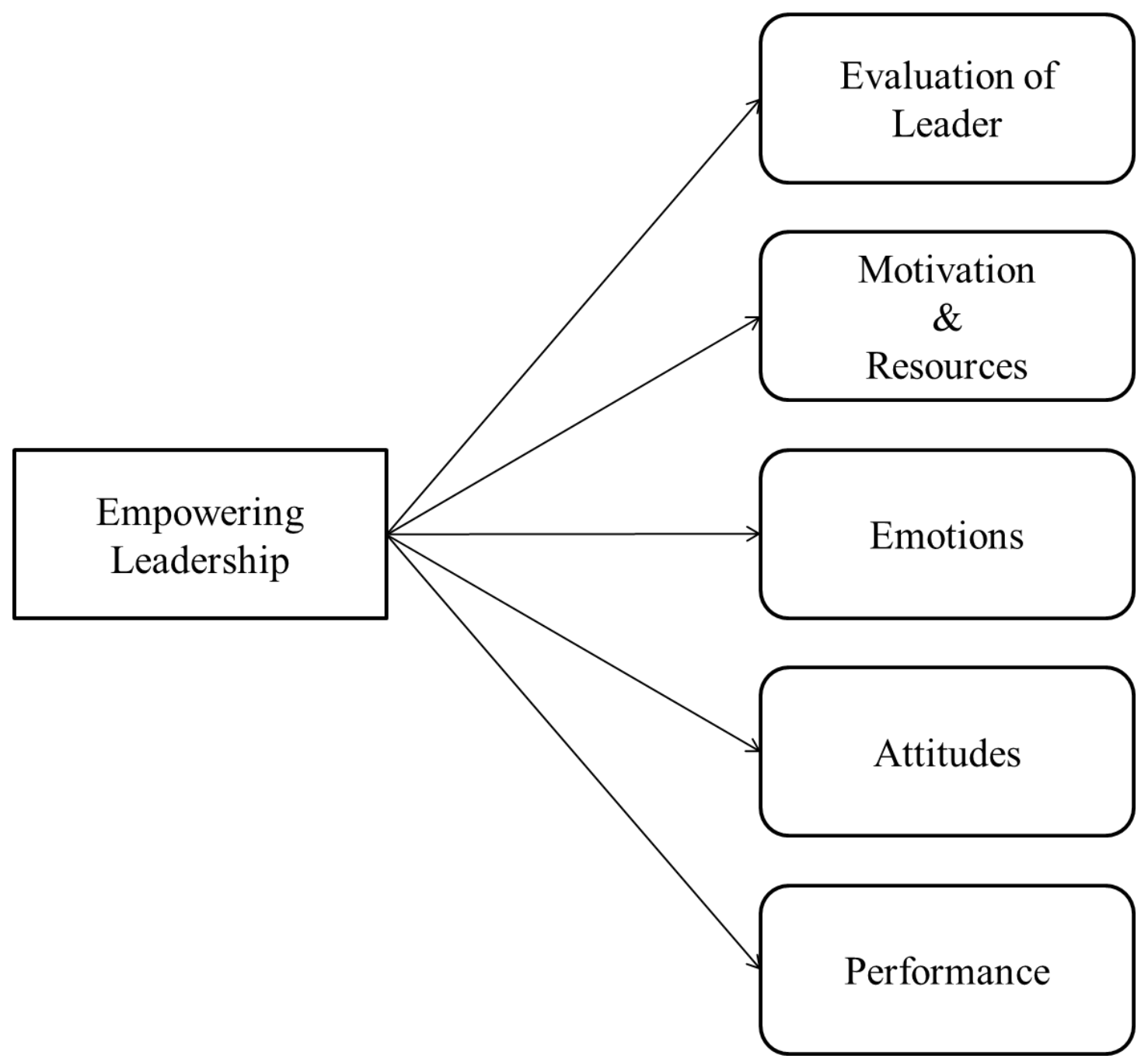

Figure 1. Outcomes of Empowering Leadership 


\section{Appendix}

Literature Review on Outcomes of Empowering Leadership Behaviors

\begin{tabular}{|c|c|}
\hline Outcomes & Name of studies \\
\hline $\begin{array}{l}\text { Evaluations of Leaders } \\
\text { Trust in the leader } \\
\text { (5 samples) }\end{array}$ & $\begin{array}{l}\text { Bobbio et al. (2012) } \\
\text { Gao et al. (2011) } \\
\text { Harris et al. (2014; study 2) } \\
\text { Zhang \& Zhou (2014; study 1) } \\
\text { Zhang \& Zhou (2014; study 2) }\end{array}$ \\
\hline $\begin{array}{l}\text { Leader-Member Exchange } \\
\text { ( } 5 \text { samples) }\end{array}$ & $\begin{array}{l}\text { Chen et al. (2007) } \\
\text { Hassan et al. (2013) } \\
\text { Kwak (2011) } \\
\text { S. Lee et al. (2016) } \\
\text { Li et al. (2016) }\end{array}$ \\
\hline $\begin{array}{l}\text { Perceived Leader Effectiveness } \\
\text { (4 samples) }\end{array}$ & $\begin{array}{l}\text { Amundsen \& Martinsen (2014a) } \\
\text { Hassan et al (2013) } \\
\text { Humborstad \& Giessner (2015) } \\
\text { Tekleab et al. (2008) }\end{array}$ \\
\hline $\begin{array}{l}\text { Motivation \& Resources } \\
\text { Self-Leadership } \\
\text { (3 samples) }\end{array}$ & $\begin{array}{l}\text { Amundsen\& Martinsen (2015; study 1) } \\
\text { Amundsen\& Martinsen (2015; study 2) } \\
\text { Tekleab et al. (2008) }\end{array}$ \\
\hline $\begin{array}{l}\text { Self-Efficacy \& OBSE } \\
\text { ( } 9 \text { samples) }\end{array}$ & $\begin{array}{l}\text { Ahearne et al. (2005) } \\
\text { Biemann et al. (2015) } \\
\text { Cheong et al. (2016) } \\
\text { Kim \& Beehr (2016a) } \\
\text { Kim \& Beehr (in pressa) } \\
\text { Kwak (2011) } \\
\text { Li et al. (2016) } \\
\text { Zhang \& Zhou (2014; study 1) } \\
\text { Zhang \& Zhou (2014; study 2) }\end{array}$ \\
\hline $\begin{array}{l}\text { Goal Orientation \& Work Effort } \\
\text { (3 samples) }\end{array}$ & $\begin{array}{l}\text { Amundsen\& Martinsen (2015; study } 1) \\
\text { Humborstad et al. (2014) } \\
\text { S. Lee et al. (2016) }\end{array}$ \\
\hline
\end{tabular}


(continued)

\begin{tabular}{|c|c|}
\hline Outcomes & Name of studies \\
\hline $\begin{array}{l}\text { Psychological Empowerment } \\
\text { ( } 25 \text { samples) }\end{array}$ & $\begin{array}{l}\text { Albrecht \& Andreetta (2011) } \\
\text { Amundsen\& Martinsen (2014b) } \\
\text { Amundsen\& Martinsen (2015; study 1) } \\
\text { Amundsen\& Martinsen (2015; study 2) } \\
\text { Auh et al. (2014) } \\
\text { Boudrias et al. (2009) } \\
\text { Chen et al. (2007) } \\
\text { Chen et al. (2011) } \\
\text { Dahinten et al. (2014) } \\
\text { Dewettinck \& Ameijde (2011) } \\
\text { Fong \& Snape (2015) } \\
\text { Kim \& Beehr (2017) } \\
\text { Konczak et al. (2000) } \\
\text { Kwak (2011) } \\
\text { Li et al. (2014) } \\
\text { Lorinkova \& Perry (2014) } \\
\text { Namasivayam et al. (2014) } \\
\text { Randolph \& Kemery (2011) } \\
\text { Raub \& Robert (2010) } \\
\text { Raub \& Robert (2013) } \\
\text { Sumpter et al. (2016) } \\
\text { Tong et al. (2015) } \\
\text { Wallace et al. (2011) } \\
\text { Yoon (2012) } \\
\text { Zhang \& Bartol (2010) }\end{array}$ \\
\hline $\begin{array}{l}\text { Role Clarity } \\
\text { (3 samples) }\end{array}$ & $\begin{array}{l}\text { Gkorezis (2016) } \\
\text { Harris et al. (2014; study 2) } \\
\text { Martínez-Córcoles et al. (2014) }\end{array}$ \\
\hline Attitudes & \\
\hline $\begin{array}{l}\text { Satisfaction } \\
\text { (12 samples) }\end{array}$ & $\begin{array}{l}\text { Amundsen\& Martinsen (2014a) } \\
\text { Amundsen\& Martinsen (2015; study 1) } \\
\text { Amundsen\& Martinsen (2015; study 2) } \\
\text { Auh et al. (2014) } \\
\text { Biemann et al. (2015) } \\
\text { Dewettinck \& Ameijde (2011) } \\
\text { Fong \& Snape (2015) } \\
\text { Kim \& Beehr (2016a) } \\
\text { Kim \& Beehr (2017) } \\
\text { Konczak et al. (2000) } \\
\text { Namasivayam et al. (2014) } \\
\text { Vecchio et al. (2010) }\end{array}$ \\
\hline
\end{tabular}


(continued)

\begin{tabular}{|c|c|}
\hline Outcomes & Name of studies \\
\hline $\begin{array}{l}\text { Commitment } \\
\text { (12 samples) }\end{array}$ & $\begin{array}{l}\text { Albrecht \& Andreetta (2011) } \\
\text { Chen et al. (2011) } \\
\text { Dahinten et al. (2014) } \\
\text { Dewettinck \& Ameijde (2011) } \\
\text { Fong \& Snape (2015) } \\
\text { Harris et al. (2014; study 2) } \\
\text { Hassan et al. (2013) } \\
\text { Kim \& Beehr (2016a) } \\
\text { Kim \& Beehr (2017) } \\
\text { Konczak et al. (2000) } \\
\text { Namasivayam et al. (2014) } \\
\text { Raub \& Robert (2013) }\end{array}$ \\
\hline $\begin{array}{l}\text { Work Engagement } \\
\text { (4 samples) }\end{array}$ & $\begin{array}{l}\text { Albrecht \& Andreetta (2011) } \\
\text { Kim \& Beehr (2016b) } \\
\text { M.C.C. Lee et al. (2017) } \\
\text { Tuckey et al. (2012) }\end{array}$ \\
\hline $\begin{array}{l}\text { Knowledge Sharing } \\
\text { ( } 2 \text { samples) }\end{array}$ & $\begin{array}{l}\text { Eze et al (2013) } \\
\text { Xue et al (2011) }\end{array}$ \\
\hline $\begin{array}{l}\text { Emotions } \\
\text { Emotional Exhaustion \& Tension \& } \\
\text { Cynicism }\end{array}$ & $\begin{array}{l}\text { Bobbio et al. (2012) } \\
\text { Cheong et al. (2016) } \\
\text { Lorinkova \& Perry (2014) }\end{array}$ \\
\hline $\begin{array}{l}\text { Performance } \\
\text { Creativity \& Innovative Behavior } \\
\text { (11 samples) }\end{array}$ & $\begin{array}{l}\text { Amundsen\& Martinsen (2014b) } \\
\text { Amundsen\& Martinsen (2015; study 2) } \\
\text { Audenaert \& Decramer (2016) } \\
\text { Chen et al. (2011) } \\
\text { Gkorezis (2016) } \\
\text { Harris et al. (2014; study 1) } \\
\text { Harris et al. (2014; study 2) } \\
\text { Jeong et al. (2016) } \\
\text { Zhang \& Bartol (2010) } \\
\text { Zhang \& Zhou (2014; study 1) } \\
\text { Zhang \& Zhou (2014; study 2) }\end{array}$ \\
\hline
\end{tabular}


(continued)

\begin{tabular}{|c|c|}
\hline Outcomes & Name of studies \\
\hline $\begin{array}{l}\text { Job Performance } \\
\text { (13 samples) }\end{array}$ & $\begin{array}{l}\text { Chen et al. (2007) } \\
\text { Cheong et al. (2016) } \\
\text { Fong \& Snape (2015) } \\
\text { Harris et al. (2014; study 2) } \\
\text { Humborstad et al. (2014) } \\
\text { Kim \& Beehr (in pressa) } \\
\text { S. Lee et al. (2016) } \\
\text { Luo et al. (2016) } \\
\text { Martin et al. (2013) } \\
\text { Raub \& Robert (2010) } \\
\text { Sumpter et al. (2016) } \\
\text { Vecchio et al. (2010) } \\
\text { Yagil (2002) }\end{array}$ \\
\hline $\begin{array}{l}\text { Contextual Performance } \\
\text { (13 samples) }\end{array}$ & $\begin{array}{l}\text { Auh et al. (2014) } \\
\text { Fong \& Snape (2015) } \\
\text { Gao et al. (2011) } \\
\text { Humborstad et al. (2014) } \\
\text { Kim \& Beehr (in pressa) } \\
\text { Li et al. (2014) } \\
\text { Li et al. (2016) } \\
\text { Lorinkova \& Perry (2014) } \\
\text { Luo et al. (2016) } \\
\text { Martin et al. (2013) } \\
\text { Raub \& Robert (2010) } \\
\text { Raub \& Robert (2013) } \\
\text { Yoon (2012) }\end{array}$ \\
\hline $\begin{array}{l}\text { Withdrawal } \\
\text { (6 samples) }\end{array}$ & $\begin{array}{l}\text { Albrecht \& Andreetta (2011) } \\
\text { Amundsen\& Martinsen (2014a) } \\
\text { Chen et al. (2011) } \\
\text { Dewettinck \& Ameijde (2011) } \\
\text { Kim \& Beehr (2016a) } \\
\text { Kim \& Beehr (2016b) }\end{array}$ \\
\hline \multicolumn{2}{|l|}{ *Other Correlates } \\
\hline $\begin{array}{l}\text { Perceived Laissez-Faire Leadership } \\
\text { Psychological Ownership } \\
\text { Meaningful Work \& Life Satisfaction } \\
\text { Thriving at Work } \\
\text { Job Crafting } \\
\text { Depression }\end{array}$ & $\begin{array}{l}\text { (-) Humborstad \& Giessner (2015) } \\
\text { (+) Kim \& Beehr (2006b) } \\
\text { (+) Kim \& Beehr (2017b) } \\
\text { (+) Li et al. (2016) } \\
\text { (+) Kim \& Beehr (in pressb) } \\
\text { (-) Kim \& Beehr (in pressb) }\end{array}$ \\
\hline Team Cohesion \& Self-Concordance & (+) Hon \& Chan (2013) \\
\hline
\end{tabular}


(+) Tung \& Chang (2011)

(continued)

Outcomes Name of studies

Team (Organizational) Efficacy and Team

Empowerment

(+) Chen et al. (2007)

(+) Günzel-Jensen et al. (2016)

(+) Hon \& Chan (2013)

(+) Srivastava et al. (2006)

Team Improvisation \& Performance \& Creativity

(+) Chen et al (2007)

(+) Hon \& Chan (2013)

(+) Magni \& Maruping (2013)

(+) Srivastava et al. (2006)

(+) Tung \& Chang (2011)

Interactional Justice Climate

(+) Li et al. (2015)

Abusive Supervision

(-) Graham (2015)

Knowledge Sharing in Teams

(+) Srivastava et al. (2006)

(+) Tung \& Chang (2011)

Notes: $*$ = excluded meta-analysis; $+=$ studies show increased levels of the variable (e.g., higher performance) resulting from empowering leadership; $-=$ decreased levels of the variable resulting from empowering leadership 